\title{
Study Upon Life Cycle of Monarthropalpus buxi Geoff. on Cluj Climatic Conditions
}

\author{
Cristina SOPORAN, Ion OLTEAN, Teodora FLORIAN* \\ ${ }^{1}$ Department Environment and Plant Protection. University of Agricultural Sciences \\ and Veterinary Medicine Faculty of Agriculture \\ * corresponding author: florian.teodora@yahoo.com \\ Bulletin USAMV series Agriculture 72(1)/2015 \\ Print ISSN 1843-5246; Electronic ISSN 1843-5386 \\ DOI 10.15835/buasvmcn-agr: 11171
}

\begin{abstract}
Monarthropalpus buxi speciesis the major pest in Buxus plants. To establish strategies to control this pest is compulsory to know the biological cycle, to act during the periods of maximum sensitivity of the species.
\end{abstract}

Keywords: life cycle, Monarthropalpus buxi Geoff, colored panels.

\section{INTRODUCTION}

Monarthropalpus buxi Geoff. shows one generation per year (Baylac,1989; Brewer et al.), but Vamvakas et al. (2006), shows that in Greece over $92 \%$ of the population has develop a single generation, and $8 \%$ of the population has develop two generations. Also BAYLAC 1989, shows that in the warmer areas of France may develop two generations. The larva feeds on leaf, impupation taking place in March and in April start flying.

\section{AIMS}

During 2011-2013 in Cluj, was monitored the life cycle of the species Monarthropalpus buxi Geoff.

\section{MATERIALS AND METHODS}

Establishing the biological cycle was done by analyzing in the laboratory, biological material collected, specifying the scheduling period of each stage of development and influence of various environmental factors in the development cycle. Adult flight period was determined using colored adhesive panels.

\section{RESULTS}

Impupation of hibernating larvae occurs in the last half of April, around the date April 18 to 22.

Pupal stage is spread over an interval of 2-3 weeks, depending on the average temperature of the day.

Flight of adults start the first days of May, when the average temperature reaches around $14^{\circ} \mathrm{C}$, and the flight occurs until the end of May.

Maximum flight curve is recorded 4-8 days after the flight start. With green and yellow colored panels can note the flight period of adults, being a method that can be used in chemical treatments warnings. Flight of adults occurs between the hours of 6 and 22 and is more intense until 12 o'clock.

Most adults of Monarthropalpus buxi Georff. fly at the height of the buxus plant. Incubation was between 12 and 22 days, being strongly influenced by the thermal value.

Larvae occur in the last days of May, the date when the attack symptoms show first. Ponta were reported on buxus leaves until the second decade 
of June, after which the larvae have evolved only. The larvae have evolved till autumn.

\section{CONCLUSION}

On climatic conditions of monitored area, Monarthropalpus buxi Geoff. has a single generation per year.

Flight adults start the first days of May.

Maximum flight curve is recorded 4-8 days after the flight start.

Ponta were reported on buxus leaves until the second decade of June.

The larvae have evolved till autumn.

\section{REFERENCES}

1. Baylac M (1989). Coexistence d'individus univoltins et partivoltins dans les populations de Monarthropalpus buxi (Lab.) du Nord de l'Europe (Diptera. Cecidomyiidae). Comptes Rendus de l' Academie des Sciences Series 3, Sciences de la Vie 308(12):337-340.

2. Brewer JW, Skuhravý V, Skuhravý M (1984). Biology, distribution and control of Monarthropalpus buxi (Laboulbène) (Diptera, Cecidomyiidae). Journal Zeitschrift für Angewandte Entomologie 97(2):167-175.

3. Vamvakas M, Kontodimas DC, Milonas PG (2006). First record of Monarthropalpus buxi in Greece and some data of its phenology. Entomologia Helenica 16:22-26. 